\title{
RESENHA DO LIVRO ENCOMENDAS TECNOLÓGICAS NO BRASIL: GUIA GERAL DE BOAS PRÁTICAS
}

Rafael Leão'

Este texto é uma resenha de Rauen, André Tortato; ${ }^{2}$ Barbosa, Caio Márcio. ${ }^{3}$ Encomendas Tecnológicas no Brasil: guia geral de boas práticas. Brasilia: Ipea, 2019. Disponivel em: <https://bit.ly/37dCveR>.

\section{SINOPSE}

Este texto é uma resenha do livro Encomendas Tecnológicas no Brasil: guia geral de boas práticas. Apesar de ser muito técnico e específico para o gestor público, a obra traz conceitos relevantes para o debate da política de inovação e o debate da política fiscal. Ao demonstrarem que a encomenda tecnológica (Etec) é não só um instrumento de apoio à inovação, mas também uma ferramenta de compra pública, os autores trazem à tona o debate sobre a qualidade do gasto público brasileiro.

Palavras-chave: compras públicas; encomenda tecnológica; políticas de inovação; risco tecnológico.

\section{INTRODUÇÃO}

O livro Encomendas Tecnológicas no Brasil: guia geral de boas práticas, de autoria de André Rauen e Caio Márcio Barbosa, objeto desta resenha, apareceu de forma muito oportuna ao ser publicado ainda no início da atual administração. Ele traz o tema da política de inovação tecnológica, sendo, portanto, um livro desse campo de pesquisa, mas inserido em um debate mais amplo, e certamente bastante necessário nos dias atuais, sobre a qualidade do gasto público brasileiro.

Superavit, restriçôes, cortes e contingenciamentos são termos ligados ao tamanho do gasto público. Onde gastamos, por que gastamos e o que pretendemos com esse gasto é um debate sobre a qualidade do gasto público em um sentido mais amplo. O como também é central: há anos discute-se no Brasil a modernização do aparato operacional e legal do sistema de compras do Estado. Este livro pretende entregar aos gestores de compras públicas um manual conceitual e operacional de uma das inovaçóes da legislaçáo de compras que surgiu nos últimos anos: a encomenda tecnológica (Etec).

\section{O QUE É E PARA QUE SERVE UMA ETEC?}

A Etec é um tipo muito particular de compra pública cujo elemento definidor é o risco tecnológico. Nela, o Estado precisa adquirir não apenas um produto ou serviço para satisfazer uma demanda específica, mas uma solução para um problema. E, quando uma solução é encomendada, parte-se do pressuposto de que aquele problema que ela pretende resolver não pode ser atendido por bens e serviços já previamente disponíveis no mercado. Se fosse assim, bastaria um processo licitatório trivial.

1. Especialista em políticas públicas e gestão governamental na Diretoria de Estudos e Políticas Setoriais de Inovação e Infraestrutura (Diset) do Ipea e editor deste Radar.E-mail: <rafael.leao@ipea.gov.br>.

2. Diretor da Diset/lpea. E-mail: <andre.rauen@ipea.gov.br>.

3. Advogado geral da União. 
É nesse aspecto que a Etec mostra sua outra faceta: ela é também uma política de inovaçáo. Mais especificamente, ela é uma política de inovação orientada pela demanda do Estado, o que ficou conhecido como política orientada por missão, ou mission-oriented policy. Diferentemente de instrumentos mais usuais de fomento à inovação em posse do Estado, como concessão de bolsas e financiamento de pesquisas, nos quais a temática da pesquisa é livre, na Etec o Estado define um problema-alvo sem solução a ser resolvido em favor da coletividade e encomenda uma solução tecnologicamente inovadora.

Aqui o conceito de risco tecnológico mostra o caráter único da Etec enquanto compra pública: a solução final pode ou náo ser entregue, pois o risco de falha no seu desenvolvimento é inexorável e nada desprezível, em virtude de conhecimento técnico-científico insuficiente em relação ao problema enfrentado. Nesse caso, foram diversas modificaçōes efetuadas na legislação referente a compras públicas vigente no Brasil há décadas. Uma das mais importantes, de ordem conceitual, admite que o Estado, em uma Etec, está pagando pelo esforço, e não pelo resultado. Diante disso, uma série de modificaçóes de ordem prática foi realizada para, de um lado, acomodar e, de outro, mitigar a possibilidade de o Estado efetivamente gastar dinheiro público em um processo que pode findar sem nenhuma entrega efetiva.

\section{QUESTÕES CONCEITUAIS PARA ALÉM DAS OPERACIONAIS}

O livro Encomendas Tecnológicas no Brasil: guia geral de boas práticas é dividido em seis capítulos, sendo quatro deles dedicados a esmiuçar aspectos técnicos e operacionais da legislação que rege a Etec. O segundo capítulo trata da instrução processual, o terceiro trata da estruturaçáo, o quarto aborda o complexo tema da precificaçáo e o quinto trata do ainda mais desafiador tema do controle. Os outros dois capítulos são introdutórios e conceituais, mas é possível extrair conceitos valiosos, implícitos, dos demais quatro.

Sem querer apenas relatar ou resumir os aspectos legais e operacionais que são devidamente tratados no livro, esta resenha busca extrair perspectivas conceituais da aridez própria da instrumentalização de um regramento de compra pública - ainda mais complexa no caso da Etec pelo conceito de risco tecnológico inerente.

Quando trata de instrução processual, no segundo capítulo, o livro mostra como as etapas prévias à realização do certame e da contrataçáo são críticas para o sucesso da encomenda. Estudos preliminares precisam demonstrar a necessidade da contratação, evidenciar o caráter único e inexorável de risco tecnológico vinculado ao problema e à soluçáo almejada, o mercado relevante e sua dimensão estimada, e os benefícios para a coletividade.

Após essa etapa, o poder público deveria, não por força de lei, mas por sugestão dos autores, abrir uma consulta pública para atrair empresas e demais interessados no assunto para mitigar assimetrias de informaçāo, compreender melhor o problema e mapear possíveis soluçôes que porventura já existam no mercado, mas que fossem de desconhecimento do setor público. A consulta seria importante para que os legalmente obrigatórios termo de referência e projeto básico fossem elaborados com alta precisão técnica.

A etapa seguinte envolveria a negociação direta com potenciais fornecedores em aspectos relacionados à forma de remuneração, às estimativas de preço e custo, à propriedade intelectual e industrial das descobertas e das soluções apresentadas, à opção de compra etc.

Em um formato mais próprio de um guia ou manual, o livro explica todos os pontos com referências precisas à legislação e seus detalhes. Mas aqui vale extrair um dado conceitual não explícito: a Etec é praticamente uma parceria público-privada (PPP). Não no sentido objetivo e legal que as PPPs foram adotadas no Brasil, especialmente vinculadas a obras de infraestrutura e concessóes de serviços públicos. Aqui, as Etecs se assemelham, no sentido amplo do termo, a uma parceria entre o setor público e o privado, que, juntos, se debruçam solidariamente sobre um determinado problema em busca de solução e negociam os termos mais adequados para a execuçáo 
da empreitada, definindo preços, formas de remuneração, propriedade intelectual etc. E isso ocorre justamente porque a incerteza imposta pelo risco tecnológico não permite formatos engessados do tipo comprador-fornecedor.

Nos capítulos seguintes, que tratam da estruturação da Etec, da questão da precificação e do controle, fica evidente que o nível de expertise técnica que a área do Estado demandante deve possuir é muito alto. O conceito de technology readiness level (TRL), ou nível de maturidade tecnológica, que é lançado ainda no início do livro, ganha relevância prática para o gestor público nesse momento. O TRL é uma ferramenta de gestão tecnológica desenvolvida pela Agência Espacial Norte-Americana (Nasa) nos anos 1970 e aplicada no Brasil pelo Instituto Nacional de Pesquisas Espaciais (Inpe), por exemplo. Segundo os autores,

essa ferramenta classifica a tecnologia ou as tecnologias necessárias ao desenvolvimento de determinada solução em função de seu nível de maturidade, o qual guarda relação direta com seu nível de risco tecnológico. Isto é, quanto mais madura é uma dada tecnologia, menor é o risco (tecnológico) nela contido (Rauen e Barbosa, 2019, p. 23).

O TRL possui nove níveis de prontidão tecnológica, sendo o nível 1 o de maior risco, pois ele ainda guarda parcos conhecimentos científicos a respeito de um determinado problema e sequer possui caminhos possíveis de solução. A escala avança até o nível 9, no qual o problema já é completamente dominado e já existem soluções tecnológicas (inclusive de mercado) com satisfatório grau de aplicação.

Então, ao trabalhar os conceitos de contratação, as formas de remuneração e o controle da execução da encomenda e do cumprimento do contrato, a equipe de Estado envolvida deve ser profunda conhecedora do assunto, o que não é necessário em situaçôes triviais de aquisição de bens e serviços para aplacar demandas rotineiras. A precificação, um dos itens mais complexos, depende do real entendimento do nível de maturidade tecnológica das soluçôes possíveis para o problema em pauta. As opções de precificação e forma de pagamento vão desde o preço fixo até as formas mais arriscadas - do ponto de vista tanto do ente privado quanto do Estado -, como o reembolso de custos com prêmios de remuneração por cumprimento de metas ambiciosas ou a redução de prazos.

Em outras palavras, as Etecs são, quase por definição, políticas públicas de caráter vertical, em virtude da profunda especificidade do conhecimento envolvido na solução de problemas típicos desse tipo de compra pública, por exemplo, o desenvolvimento de novas fontes energéticas, novos tratamentos médicos e novas soluçôes de engenharia. E isso novamente insere o livro em uma discussão mais ampla sobre que tipo de política pública econômica é mais desejada: políticas de cunho vertical ou políticas de cunho horizontal.

Essa diferenciação, que deveria ser restrita ao seu objetivo didático e pedagógico de organizar o conhecimento sobre os diversos instrumentos de política pública existentes, tornou-se um critério de aceitação ou não desses instrumentos. Aqui vale dizer: as Etecs são vastamente utilizadas há décadas pelas naçôes mais desenvolvidas, especialmente os Estados Unidos, que se valem de políticas orientadas por missão a pretexto de defesa, segurança, energia e saúde para solucionarem problemas de repercussão ampla e coletiva e, ao mesmo tempo, alavancarem o desenvolvimento científico e tecnológico do país.

\section{IMPLICAÇÕES PRÁTICAS}

Em resumo: o livro tem como meta apontar, em termos práticos, com indicação de legislação e sugestão de boas práticas, como o gestor público deve proceder em relação às Etecs. Contudo, ele também traz implicitamente questóes conceituais importantes para discussóes mais amplas sobre o funcionamento do Estado brasileiro.

Primeiramente, deve-se citar a modernização dos instrumentos de compras e aquisiçôes do Estado, bem como o debate sobre a qualidade do gasto público no Brasil. Para além do quanto gastamos, o livro mostra um instrumento que pode ser utilizado com segurança institucional para refinar os objetivos que se pode alcançar com as compras públicas. 
Em segundo lugar, ele traz o debate sobre a pertinência de se utilizar o conceito de política vertical e política horizontal para se escolherem instrumentos de política pública. No caso da política de inovação, o conceito de política pública orientada por missão e a complexidade associada à elaboração de uma Etec deixam claro seu caráter setorial e vertical. A implicação disso para a discussão sobre a ação do Estado brasileiro é nítida: pouco importa se vertical ou horizontal; importa apenas se a política tem potencial real de gerar efeitos positivos para o conjunto da economia do país. 